Pesq. Vet. Bras. 28(1):63-69, janeiro 2008

\title{
Aspectos clínicos, epidemiológicos e patológicos da infecção natural em bovinos por Trypanosoma vivax na Paraíba ${ }^{1}$
}

\author{
Jael S. Batista ${ }^{2 \star}$, Francisco Silvestre B. Bezerra ${ }^{3}$, Rodrigo A. Lira ${ }^{4}$, José \\ Ricardo G. Carvalho ${ }^{4}$, Antonio M. Rosado Neto ${ }^{5}$, Alinson A. Petrij e Marta \\ Maria G. Teixeira ${ }^{7}$
}

\begin{abstract}
Batista J.S., Bezerra F.S.B., Lira R.A., Carvalho J.R.G., Rosado Neto A.M., Petri A.A. \& Teixeira M.M.G. 2008. [Clinical, epidemiological and pathological signs of natural infection in cattle by Trypanosoma vivax in Paraíba, Brazil.] Aspectos clínicos, epidemiológicos e patológicos da infecção natural em bovinos por Trypanosoma vivax na Paraíba. Pesquisa Veterinária Brasileira 28(1):63-69. Departamento de Ciências Animais, Universidade Federal Rural do Semi-árido, BR 110 Km 47, Caixa Postal 147, Mossoró, RN 59625-900, Brazil. E-mail: jaelsbatista@ hotmail.com

Two outbreaks of trypanosomiasis by Trypanosoma vivax, reported in cattle, occurred on two farms located in the state of Paraíba, northeastern Brazil. The epidemiology, clinical signs and pathology of the disease were studied from May 2005 to November 2006. T. vivax was identified morphologically and by polymerase chain reaction test (PCR). The affected cattle presented anorexia, depression, fever, anemia, weight loss, reduction in milk production, transitory blindness, abortion and some nervous signs as nystagmus, tetany and bruxism. All cattle that presented nervous signs died. Necropsy findings were enlarged lymph and spleen, serous atrophy of the fat depots, proeminence of the splenic white pulp, hydropericardium and pericardial petechiae and ecchymoses on the epicardium. Histologically there was meningoencephalitis. The treatment of the clinical cases with diminazena aceturate was efficient with clearance of the parasite from the blood or disappearance of clinical signs in up to 2 months after the beginning of the outbreak on the two farms studied. The epidemiologic factors favoring the occurrence of the outbreak were the abundance of mechanical vectors, as tabanids and Stomoxys sp., and the introduction into the herd of cattle from farms where the disease occurred. It is suggested that the semiarid of the Brazilian Northeast is an enzootic instability region for trypanosomiasis due to its prolonged periods of drought and high temperatures, constituting during most part of the year an unfavorable environment for the development of vectors.
\end{abstract}

INDEX TERMS: Trypanosoma vivax, trypanosomiasis, cattle, outbreak, Brazilian Northeast, semiarid.

\footnotetext{
${ }^{1}$ Recebido em 6 de fevereiro de 2007.

Aceito para publicação em 28 de janeiro de 2008.

2 Departamento de Ciências Animais, Universidade Federal Rural do Semi-árido (UFERSA), BR $110 \mathrm{Km} \mathrm{47,} \mathrm{Presidente} \mathrm{Costa} \mathrm{e} \mathrm{Silva,} \mathrm{Cx.}$ Postal 147, Mossoró, RN 59625-900, Brasil. *Autor para correspondência: jaelsbatista@hotmail.com

3 Pós-graduando do Programa de Ciência Animal, Laboratório de Patologia Veterinária, UFERSA, Mossoró, RN.
}

\footnotetext{
${ }^{4}$ Graduando em Medicina Veterinária, UFERSA, Mossoró, RN.

${ }^{5}$ Médico veterinário autônomo, Rua Santana 12, Presidente Costa e Silva, Mossoró, RN 59625-640.

${ }^{6}$ Médico veterinário autônomo, Rua Wenceslau Brás 903, Paredões, Mossoró, RN 59618-140.

7 Departamento de Parasitologia, Instituto de Ciências Biomédicas, Universidade de São Paulo (USP), Av. Professor Lineu Prestes 1374, Cidade Universitária, São Paulo, SP 05508-000, Brasil.
} 
RESUMO.- Descrevem-se dois surtos de tripanossomíase por Trypanosoma vivax em bovinos, ocorridos em dois estabelecimentos do alto sertão da Paraíba. Os sinais clínicos, a patologia e a epidemiologia da doença foram estudados no período de maio de 2005 a novembro de 2006. $T$. vivax foi identificado em esfregaços da capa leucocitária e mediante a reação em cadeia da polimerase (PCR). Os animais afetados apresentaram anorexia, depressão, febre, anemia, perda de peso, redução da produção leiteira, cegueira transitória, aborto e sinais nervosos caracterizados por incoordenação motora, salivação, opistótono, nistagno, tetania e bruxismo. Todos os animais que apresentaram sintomatologia nervosa morreram. As alterações macroscópicas observadas em um bovino submetido à necropsia foram aumento de volume dos linfonodos, atrofia serosa dos depósitos de gordura, aumento de volume do baço com evidência da polpa branca, hidropericárdio, além de petéquias e equimoses no epicárdio. Histologicamente havia meningoencefalite. $O$ controle da doença na propriedade com tratamento específico dos casos clínicos com aceturato de diminazene foi eficiente, pois após o tratamento não se verificou mais a presença do parasita em esfregaços sanguíneos nem evidência clínica da enfermidade em até 2 meses após o início do surto. Os fatores epidemiológicos favoráveis à ocorrência dos surtos foram a abundância de vetores mecânicos, como tabanídeos $e$ Stomozys spp., e a entrada, no rebanho, de animais oriundos de propriedades onde ocorreu a doença em questão. Sugere-se que o semi-árido do Nordeste, devido a períodos prolongados de secas e altas temperaturas, é região de instabilidade enzoótica para a tripanossomíase, em conseqüência, provavelmente, ao ambiente desfavorável para o desenvolvimento de vetores durante a maior parte do ano.

TERMOS DE INDEXAÇÃO: Trypanosoma vivax, tripanossomíase, bovino, surto, semi-árido nordestino.

\section{INTRODUÇÃO}

Tripanossomíases são doenças provocadas por protozoários patogênicos do gênero Trypanosoma, que têm larga distribuição e importância econômica na África, principalmente em áreas ocupadas pelo seu vetor biológico, a mosca tsetse (Gardiner et al. 1989). No Oeste da África, Trypanosoma vivax é considerado o mais patogênico e importante tripanossoma de bovinos. A adaptação à transmissão mecânica por insetos hematófagos, tais como tabanídeos e Stomoxys spp., permitiu a expansão de $T$. vivax para América Central, América do Sul e Caribe (Silva et al. 2003).

O primeiro relato de $T$. vivax em bovinos na América do Sul foi na Guiana Francesa (Leger \& Viene 1919). Outro surto foi descrito na Costa Atlântica da Colômbia em 1931, quando ocorreu uma enfermidade de caráter crônico caracterizada por anemia, perda de peso e enfraquecimento progressivo em animais que apresentaram o parasita em esfregaços sangüíneos (Zapata 1931).
A ocorrência $T$. vivax no Brasil foi registrada pela primeira vez em búfalos no Estado do Pará, no ano de 1972 (Losos \& Ikede 1972). Desde então, esse parasita estava restrito ao norte do país, quando em 1995, T. vivax foi identificado em bovinos durante um surto ocorrido na região pantaneira de Poconé, Pantanal do Mato Grosso (Silva et al. 1996).

Na região Nordeste, o primeiro surto de tripanossomíase por T. vivax foi diagnosticado em 2002. Na propriedade, localizada no município de Catolé do Rocha, sertão da Paraíba. Neste surto, 64 bovinos leiteiros adultos adoeceram e 11 morreram de um rebanho de 130 animais. Os bovinos afetados apresentaram febre, anemia, perda de peso, hipoglicemia e sinais nervosos caracterizados por incoordenação, tremores musculares, cegueira transitória e/ou permanente, hipermetria, além de lesões histológicas caracterizadas por meningoencefalite e malácia (Batista et al. 2007). A patogenicidade do isolado foi confirmada através da reprodução experimental da doença em 4 ovinos inoculados com $1 \mathrm{ml}$ de sangue contendo $1,85 \times 10^{5}$ tripomastigotas. Os animais infectados apresentaram febre, anemia, leucopenia, perda de peso e miocardite (Batista et al. 2006).

Linhares et al. (2006) descreveram outro surto de tripanosomíase por $T$. vivax em um rebanho bovino da raça Brahman, composto de 250 animais recém introduzidos em uma propriedade no município de Formosa do Araguaia no estado do Tocantins, procedente de São Paulo. Dentre nove bovinos que apresentaram sinais de debilidade, emagrecimento, edema de barbela, febre e palidez de mucosa, observou-se a presença de $T$. vivax no esfregaço sangüíneo de três animais, cujos hematócritos apresentaram valores que variaram de $15-20 \%$. Segundo os autores, a ocorrência do surto confirma o risco em potencial existente nas situações envolvendo o movimento de rebanhos bovinos de áreas livres para áreas enzoóticas.

Em razão dos poucos relatos da presença de $T$. vivax no Nordeste, o objetivo do presente trabalho consistiu em registrar a ocorrência de surtos de tripanossomíase causados por T. vivax em bovinos leiteiros no Estados da Paraíba, bem como caracterizar seus aspectos epidemiológicos, clínicos e patológicos.

\section{MATERIAL E MÉTODOS}

Durante o período de maio de 2005 a novembro de 2006 realizou-se, em intervalos mensais, o acompanhamento da evolução das alterações clínicas e a obtenção de dados epidemiológicos em duas propriedades de bovinos leiteiros, localizadas no alto sertão da Paraíba, que apresentaram histórico clínico da infecção natural por Trypanosoma vivax.

Por ocasião de cada visita às propriedades, foram realizados exames clínicos e avaliados freqüência cardíaca e respiratória, aspectos das mucosas aparentes e volume dos linfonodos externos à palpação, assim como o comportamento, estado geral e a produção leiteira. Foi realizado ainda, junto aos proprietários e tratadores dos animais, um estudo das alterações reprodutivas ocorridas por ocasião do surto. 
Em cada animal foram coletados, por punção da veia jugular, $5,0 \mathrm{ml}$ de sangue, que foram acondicionados em tubos estéreis contendo ácido etilenodiamino tetra-acético (EDTA) e destinados à realização de hemogramas completos. Por ocasião dos exames hematológicos, realizou-se o diagnóstico da tripanossomíase através de esfregaços da capa leucocitária. A contagem de tripanossomas no sangue periférico foi realizada mediante técnica de Brener (1961). Nos animais com exames parasitológicos positivos foi realizado o diagnóstico definitivo da infecção por $T$. vivax através da reação em cadeia da polimerase (PCR), conforme metodologia descrita por Ventura et al. (2001).

Foi realizada a necropsia em uma vaca com sinais clínicos de distúrbio nervoso e coletados fragmentos dos órgãos das cavidades torácica e abdominal e do sistema nervoso central, os quais foram fixados em solução tamponada de formol a $10 \%$, incluídos em parafina, cortados a uma espessura de 5 microns e corados pela Hematoxilina e Eosina (HE).

\section{RESULTADOS}

\section{Histórico, sinais clínicos e diagnóstico da doença}

Surto 1. O surto da infecção por Trypanosoma vivax em bovinos ocorreu em uma fazenda localizada no município de São José. Na propriedade havia 36 vacas mestiças de Pardo Suíço, destas 24 em lactação, e 30 bezerros. Os animais eram criados em regime semi-intensivo, alimentados à base de pastagem nativa e suplementados com capim elefante, sorgo, ração comercial e sal mineral.

No início de julho de 2005 ocorreram os primeiros casos da enfermidade. Inicialmente, 14 vacas apresentaram queda pronunciada da produção diária de leite (de 15 litros diários, em média, para 2 litros). Clinicamente, os animais apresentaram depressão, anorexia, febre variável de $40,5-42,0^{\circ} \mathrm{C}$, aumento da freqüência cardíaca e respiratória, opacidade de córnea, mucosas pálidas, aumento dos linfonodos palpáveis e perda de peso. Três vacas abortaram e duas pariram bezerros fracos que morreram nos primeiros dias de vida. Oito vacas apresentaram cegueira transitória e três apresentaram sintomatologia nervosa caracterizada por incoordenação motora, salivação, opistótono, nistagno, tetania e bruxismo. Todos os animais que apresentaram sintomatologia nervosa morreram. A morte ocorreu entre 4 e 8 dias após o início dos sinais clínicos.

O hemograma realizado nas 36 vacas do rebanho demonstrou que 17 animais apresentaram hematócritos que variaram de $15-22 \%$, baixos valores nas contagens de hemácias e teores de hemoglobina, indicando que os mesmos desenvolveram anemia intensa. O quadro de anemia foi acompanhado de leucopenia com linfocitose.

Nos exames da capa leucocitária, observou-se que 15 vacas apresentaram-se positivas para $T$. vivax, com parasitemia que variou de $1,7 \times 10^{5}$ a $120 \times 10^{5}$ parasitas por $\mathrm{ml}$ de sangue. Na reação em cadeia da polimerase houve a amplificação de um fragmento do gene Spliced Leader (SL), de 210 pares de base de DNA, espécie-específico para T. vivax, estabelecendo-se dessa forma o diagnóstico definitivo da infecção por esse hemoprotozoário.
Após o diagnóstico da enfermidade, os animais positivos foram tratados com aceturato de diminazeno (Ganaseg®) na dose de $5 \mathrm{mg} / \mathrm{kg}$. No primeiro dia pós-tratamento, verificou-se a ausência de T. vivax em esfregaços sanguíneos.

O proprietário informou que anualmente, durante o período seco (agosto-dezembro), alugava pasto aos criadores que possuíam pouca disponibilidade de forragem. Durante a investigação epidemiológica, foi constatado que a ocorrência do surto coincidiu com a permanência na propriedade estudada de animais provenientes de uma fazenda onde $T$. vivax foi identificado por Batista et al. (2007). O proprietário relatou que a população de mutucas (Tabanus spp.) e moscas dos estábulos (Stomoxys calcitrans) esteve aumentada durante a ocorrência do surto.

Na segunda visita à propriedade, realizada em agosto de 2005, observou-se que uma vaca com histórico de sintomatologia nervosa e que já havia sido tratada anteriormente, apresentou recidiva clínica da enfermidade, onde se confirmou a presença do T. vivax através de esfregaços da capa leucocitária. O animal foi novamente tratado com a droga tripanocida. Entretanto, apresentou em 20 dias após o novo tratamento, recidiva parasitológica e por fim, permaneceu em decúbito, sendo sacrificado e submetido à necropsia.

Na terceira visita à propriedade, realizada em setembro de 2005, observou-se repetição de cio em cinco vacas que apresentaram exames parasitológicos positivos e que foram submetidas à monta natural por ocasião do início do surto. Observou-se também recuperação da produção leiteira para valores anteriores aos do surto. 0 hemograma demonstrou-se com parâmetros dentro da normalidade para a espécie e não foram constatadas evidências de sinais clínicos. Em nenhum dos animais avaliados o parasita foi identificado.

Surto 2. O surto ocorreu em julho de 2006 no município de Belém do Brejo do Cruz, onde de um total de 75 vacas, em que 50 estavam em lactação, 10 adoeceram e destas sete morreram. O proprietário informou que os animais debilitados, em final de lactação ou gestação, permaneceram cerca de quatro meses em um pasto vizinho à propriedade onde ocorreu o Surto 1 e que o surto ocorreu após o retorno desses animais à propriedade.

Antes do diagnóstico de tripanossomíase, cinco vacas que apresentavam anorexia, depressão, febre e redução da produção de leite foram tratadas para tristeza parasitária com cloridrato de oxitetraciclina, porém não responderam ao tratamento. Houve evolução da enfermidade, que se agravou e por fim os animais permaneceram em decúbito esternal. Todos os cinco animais morreram após um curso clínico de 8 dias.

No mesmo período, outras duas vacas em gestação permaneceram em decúbito esternal após o parto. Devido às manifestações clínicas similares à paresia puerperal, esses animais foram tratados com gluconato de cálcio, no entanto, não houve resposta ao tratamento e os ani- 
mais morreram após o curso clínico de 5 dias. Sete dias após a morte destes dois animais, mais três vacas, onde duas delas estavam no terço final da gestação, adoeceram e abortaram.

Foi realizada a pesquisa de $T$. vivax no esfregaço sangüíneo de 20 vacas, sendo identificado o parasita em seis, dois dos quais eram assintomáticos. Uma vez que o parasita foi verificado em bovinos aparentemente saudáveis, o proprietário resolveu medicar todos os bovinos do rebanho com aceturato de diminazene. Mesmo após seis aplicações em intervalos semanais com essa droga tripanocida, uma vaca com sinais nervosos apresentou recidiva clínica da enfermidade. Em agosto de 2006 e nas visitas subseqüentes, não foi verificado o parasita nos esfregaços sangüíneos, ou evidência clínica da enfermidade.

\section{Patologia}

As alterações macroscópicas observadas na vaca submetida à necropsia foram: aumento de volume dos linfo-

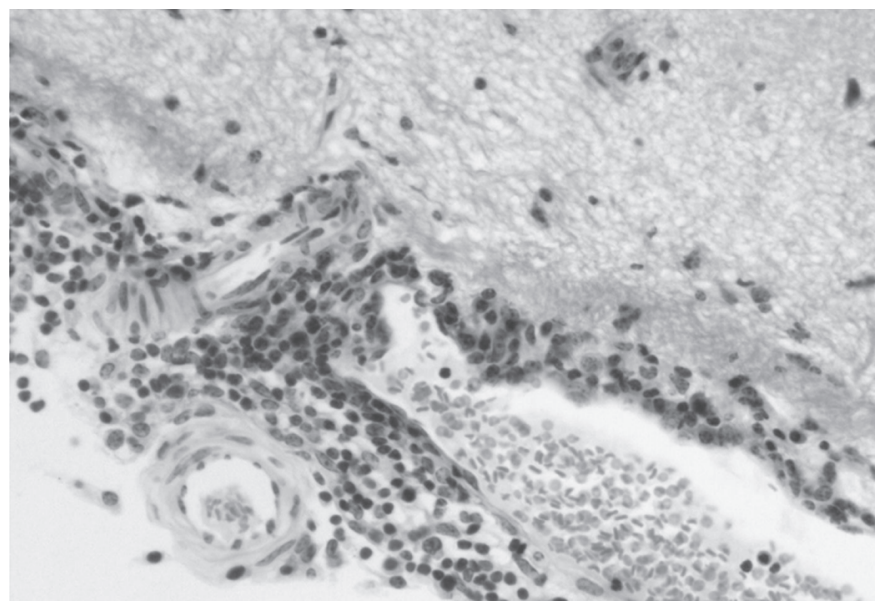

Fig.1. Meningite linfoplasmocitária, na infecção natural de bovino por Trypanosoma vivax. HE, obj.40x.

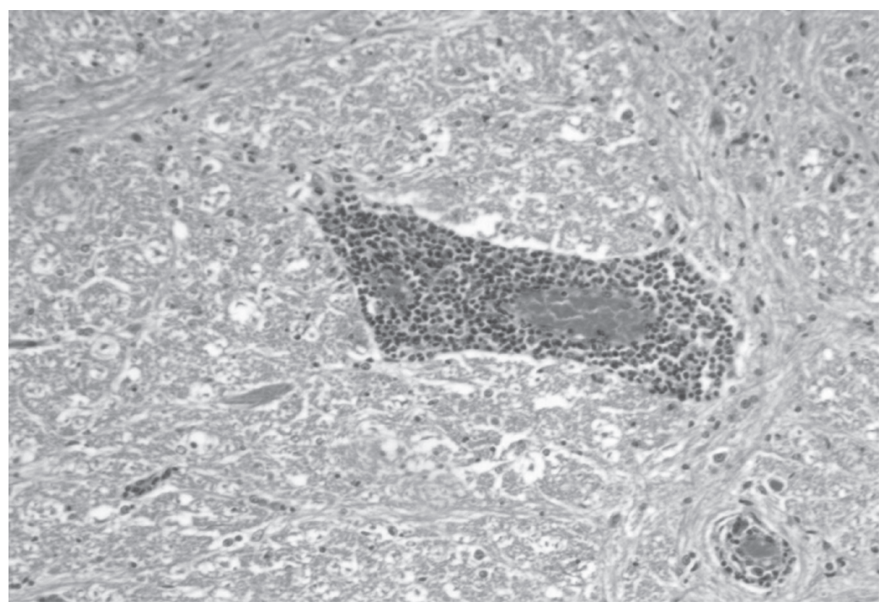

Fig.2. Infiltrado inflamatório perivascular mononuclear no tálamo, na infecção natural de bovino por Trypanosoma vivax. HE, obj.20x. nodos, atrofia serosa dos depósitos de gordura, mais evidente no epicárdio, aumento de volume do baço com evidência da polpa branca, acúmulo de líquido no saco pericárdio e hemorragias petequiais e equimóticas no epicárdio.

Histologicamente observou-se no baço e nos linfonodos hiperplasia dos folículos linfóides com grande número de plasmoblastos. Importantes lesões foram observadas no sistema nervoso central e consistiam em meningoencefalite. A meningite foi caracterizada pela presença de infiltrado inflamatório constituído por linfócitos, plasmócitos e células morulares (células de Mott) (Fig.1). O infiltrado inflamatório envolveu as meninges das regiões do córtex parietal, temporal e cerebelo. A encefalite foi evidenciada por infiltrados perivasculares (de até $14 \mathrm{ca}-$ madas de células) compostos principalmente de linfócitos, plasmócitos, macrófagos, células Mott e, ocasionalmente, linfoblastos e plasmoblastos (Fig.2). Tais infiltrados envolveram um maior número de vasos na substância branca do tálamo, cápsula interna e pedúnculo cerebelar. A encefalite também foi observada no telencéfalo, na altura dos lobos parietal, temporal e occipital, porém em menor intensidade. Não foram observadas lesões degenerativas (malácia).

\section{DISCUSSÃO}

Os relatos iniciais de surtos de Trypanosoma vivax em bovinos no Brasil provocaram por parte de pesquisadores e criadores o temor de que ocorressem altas taxas de morbidade e mortalidade observadas na África. No entanto, estudo da patogenicidade de T. vivax (Paiva et al. 2000) realizado no período de abril 1997 a julho 1999, mediante o acompanhamento clínico, laboratorial e anatomopatológico de bovinos em propriedades onde o parasita havia sido detectado no Estado do Mato Grosso, permitiu concluir que $T$. vivax não foi responsável pelos casos clínicos observados, uma vez que os animais considerados doentes, parasitados ou não, apresentaram alterações clínico patológicas compatíveis às observadas em casos de intoxicação por plantas tóxicas. Os autores sugerem que, uma vez que as infecções por $T$. vivax apresentam sinais clínicos semelhantes aos de outras doenças, para o diagnóstico da tripanossomíase deve ser realizado diagnóstico diferencial com outras enfermidades, dado que a constatação do parasita no sangue não significa que os animais estejam afetados pela tripanossomíase.

Nos surtos descritos neste trabalho, ocorridos no sertão da Paraíba, sinais clínicos e laboratoriais como a anemia, a leucopenia, a febre associada à parasitemia elevada, aliados ao diagnóstico do parasita por PCR, à recuperação dos animais enfermos após o tratamento específico e ainda à ausência de infecção por outros hematozoários confirmam o diagnóstico de tripanossomíase por $T$. vivax.

A entrada de animais oriundos de outros rebanhos onde foi constatada a presença de T. vivax, ocorrida no Surto 
1, bem como a permanência dos animais da fazenda onde ocorreu o Surto 2 em um pasto vizinho à propriedade onde ocorreu o Surto 1, foram os prováveis fatores epidemiológicos que favoreceram a ocorrência dos surtos descritos no presente trabalho. Tendo em vista a ocorrência de um surto de tripanossomíase por T. vivax descrito por Batista et al. (2007) na microrregião onde o presente estudo foi estruturado, é possível que a enfermidade esteja disseminada no sertão da Paraíba. A similaridade dos sinais clínicos da tripanossomíase com outras doenças, bem como o desconhecimento da enfermidade por parte de criadores e médicos veterinários, dificulta o diagnóstico definitivo. Dessa forma, diagnóstico parasitológico mediante esfregaços da capa leucocitária, nos quais se verifica a presença do parasita, associado aos sinais clínicos e à anemia verificados no presente estudo devem ser considerados no diagnóstico diferencial de enfermidades que ocorrem na região.

Outro fator epidemiológico que favoreceu a ocorrência da enfermidade foi a presença de vetores mecânicos como tabanídeos e Stomoxys sp. que, conforme foi relatado, estiveram aumentados entre os meses de maio e julho de 2005 e 2006. Fato semelhante foi também verificado por Batista et al. (2007) que relatam ocorrência de surto em bovinos no município de Catolé do Rocha, em maio de 2002. O aumento da população de vetores mecânicos nesse período foi também atribuído pelo citado autor à ocorrência do surto. A adaptação à transmissão mecânica por uma variedade de espécies de dípteros hematófagos dificulta determinar os vetores responsáveis pela transmissão do $T$. vivax nas propriedades onde são relatados os surtos deste trabalho. Em Cuba, Cordoves et al. (1982) divulgaram uma lista de nove espécies, das famílias Culicidae, Ceratopogonidae, Simuliidae e Muscidae, incriminadas na transmissão mecânica de $T$. vivax. Otte \& Abuabara (1991) confirmaram a transmissão mecânica por tabanídeos ao verificar que estes vetores são capazes de transmitir $T$. vivax de um animal altamente parasitado quando o repasto sanguíneo é interrompido, seguido da alimentação em um período inferior a 10 minutos em outro animal saudável. Otte et al. (1994) associam a ocorrência do parasita na Colômbia ao aumento da população de tabanídeos no período chuvoso.

A ocorrência de surtos após a entrada no rebanho de animais oriundos de propriedades onde ocorreu a doença, além da abundância de vetores mecânicos verificados no presente estudo, sugerem que a região semi-árida, devido a períodos prolongados de secas e altas temperaturas, é área de instabilidade enzoótica para a tripanossomíase, provavelmente em conseqüência do ambiente desfavorável para o desenvolvimento de vetores durante a maior parte do ano. Situação semelhante ocorre na região semi-árida com a tristeza parasitária. Como Boophilus microplus não sobrevive a períodos prolongados de seca, os bovinos não são infectados e não desenvolvem imunidade ativa, dessa forma, surtos ocorrem quando o parasita, vindo de outras regiões, se multiplica durante o período chuvoso, ou quando animais da região semi-árida são transportados para regiões de estabilidade enzoótica (Riet-Correa et al. 2003).

O eritrograma dos animais do rebanho revelou acentuada queda na contagem de hemácias, hematócrito e dos teores de hemoglobina, indicando que os animais desenvolveram anemia intensa. A ocorrência da anemia confirma os resultados de trabalhos que relatam essa alteração hematológica como a mais freqüentemente observada em animais infectados naturalmente ou experimentalmente por T. vivax (Silva et al. 1999, Espinosa et al. 2000, Silva \& Dávila 2001, Batista et al. 2006). A anemia provocada por $T$. vivax é considerada multifatorial, sendo atribuída à hemólise intra e extravascular, diminuição ou inibição da eritropoiese e hemorragias (Holmes 1997).

A leucopenia com linfocitose foi a principal característica do leucograma dos animais do rebanho em estudo. Dados do presente trabalho são semelhantes aos obtidos por Espinosa \& Aso (1992), que analisaram a leucopenia como principal alteração no leucograma em bovinos infectados experimentalmente com uma cepa venezuelana de T. vivax. Para esses autores, a leucopenia parece ser uma ocorrência importante em infecções por T. vivax em bovinos, ovinos e caprinos.

Os casos de aborto, mortalidade perinatal e repetição de cio observados, sugerem que T. vivax deve ser considerado como mais um agente etiológico de alterações reprodutivas no semi-árido nordestino. Na África, a tripanossomíase em bovinos causa consideráveis perdas econômicas devido à redução da fertilidade do rebanho por provocar desordens reprodutivas como aborto, anestro temporário ou permanente além de ciclos estrais anormais (Sekoni 1994). Casos de aborto em bovinos provocados por T. vivax também foram relatados por Silva et al. (2004) durante surtos ocorridos em áreas inundáveis da Bolívia e no Pantanal do Mato Grosso. Em surto descito no município de Catolé do Rocha, sertão da Paraíba, seis vacas positivas para $T$. vivax apresentaram, além de febre e anemia severa, abortamento no terço final da gestação, e uma vaca pariu um bezerro que morreu imediatamente após o parto (Batista et al. 2007).

O controle da doença realizado no Surto 1, com o tratamento específico somente dos casos clínicos foi eficiente, uma vez que, com exceção de um animal com sintomatologia nervosa, nos demais animais medicados não houve a ocorrência de recidivas da tripanossomíase. Esse fato sugere ser desnecessário o tratamento massal do rebanho, uma vez que além de anti-econômica, esta prática pode favorecer a ocorrência de resistência à droga tripanocida. A rapidez com a qual os tripanossomos desenvolvem resistência a estes medicamentos tem complicado muito o tratamento e controle da tripanossomíase na África (Schunefeld et al. 1987). Nas áreas onde há ausência da transmissão cíclica do T. vivax por mosca tsé-tsé e a transmissão ocorre mecanicamente, os méto- 
dos de controle e tratamento são relativamente simples. O tratamento precoce, visto que a parasitemia é sempre mais alta nos períodos iniciais da doença, provoca a rápida cessão da transmissão mecânica por insetos, se este for o principal modo de transmissão (Stephen 1986). Como forma de prevenir resistência a drogas tripanocidas, Vargas \& Arellano (1997) sugerem que no continente americano a administração de droga tripanocida deve ser restrita somente aos animais parasitados, devendo-se evitar a aplicação massiva da droga no rebanho.

O desaparecimento da enfermidade cerca de três meses após o início do surto, tal como foi verificado por Batista et al. (2007), sugere que a tripanossomíase na região semi-árida do nordeste tende à rápida estabilização. Segundo Desquesnes \& Gardiner (1993), a estabilização enzoótica da tripanossomíase por $T$. vivax nas Américas é atribuída à transmissão mecânica. A adaptação à transmissão mecânica restringiu a variação antigênica, característica marcante do parasita na África, que está relacionada a sua patogenicidade (Jones \& Dávila 2001). Um estudo comparativo de isolados de T. vivax em quatro regiões da Colômbia verificou, mediante a prova imune lise, que os parasitas das áreas estudadas são antigenicamente relacionados, pertencentes, portanto, ao mesmo seronema (Dirie et al. 1993).

A forma neurológica central, frequentemente relatada na tripanossomíase provocada por tripanossomas salivários no continente africano deve ser considerada como uma importante manifestação da enfermidade nas Américas. Rodrigues et al. (2005) relataram surtos da tripanossomíase por T. evansi em eqüinos no Rio Grande do Sul, e verificaram a associação de distúrbios neurológicos a uma encefalite necrosante grave com presença de células Mott. Sinais nervosos em bovinos que apresentaram meningoencefalite, como observados no presente trabalho, também foram descritos por Batista et al. (2007) durante um surto ocorrido por T. vivax no município de Catolé do Rocha, sertão da Paraíba. Outra importante semelhança com relação a esse surto é que os animais que apresentaram sintomatologia nervosa, na sua maioria apresentaram recidivas clínicas e morreram. Tal fato pode confirmar a afirmação do citado autor, que sugere a localização do parasita no sistema nervoso central como um agravante no prognóstico da enfermidade, por dificultar a resposta ao tratamento específico, bem como elevar a mortalidade dos animais.

\section{REFERÊNCIAS}

Batista J.S., Riet-Correa F., Barbosa R.C. \& Guerra J.L. 2006. Infecção experimental por Trypanosoma vivax em ovinos. Pesq. Vet. Bras. 26(1):31-37.

Batista J.S., Riet-Correa F., Teixeira M.M.G., Madruga C.R., Simões S.V.D. \& Maia F. 2007. Trypanosomiasis by Trypanosoma vivax in cattle in the Brazilian semiarid: Description of an outbreak and lesions in the nervous system. Vet. Parasitol. 143:174-181.

Brener Z. 1961. Contribuição ao estudo da terapêutica experimental da doença de Chagas. Tese de Livre Docência, Universidade Federal de Minas Gerais, Belo Horizonte. 90p.
Cordoves C.O., Fernandes C., Garcia-Avila I. \& Broche G.R. 1982. Trypanosoma vivax (Ziemann, 1905). Lista de transmisores mecánicos en Cuba. Revta Cubana Cienc. Vet. 13(2):219-221.

Desquesnes M.T. \& Gardiner P.R. 1993. Epidemilogie de la trypanosomes bovine (Trypanosoma vivax) en Guayane Française. Rev. Elevage Méd. Vét. Pays Trop. 46:463-470.

Dirie M.F., Otte M.J., Thatthi R. \& Gardiner P.R. 1993. Comparative studies of Trypanosoma vivax. Parasitology 106:21-29.

Espinosa E. \& Aso P.M. 1992. Valores hematológicos de bovinos infectados experimentalmente com um aislado venezolano de Trypanosoma vivax. Parte II. Leucócitos. Revta Salud Animal 14:4149.

Espinosa E., Sandoval E., Mavare M., Gonzalez N. \& Rangel L. 2000. Comparación de la serie eritrocítica y leucocítica en ovejas y cabras infectadas con Trypanosoma vivax. Vet. Tropical 1(25):29-39.

Gardiner P.R., Assoku R.K.G., Whitelaw D.D. \& Murray M. 1989. Haemorragiclesions resulting from Trypanossoma vivax infection in Ayrshire cattle. Vet. Parasitol. 31(3-4):187-198.

Holmes P.H. 1997. Pathophysiology of parasitic infections. Parasitology 94:829-851.

Jones T. \& Dávila A.M.R. 2001. Trypanosoma vivax out of Africa. Trends in Parasitology 2(17):99-101.

Jones T.C., Hunt R.D. \& King N.W. 2000. Patologia Veterinária. $1^{\mathrm{a}}$ ed. brasileira. Editora Manole, São Paulo.

Leger M. \& Vienne M. 1919. Epizootie a trypanosomes chez lês bovides de la Guayane Francais. Bulln Société Pathol. Exotique 12:216-258.

Linhares G.F.C., Filho F.C.D., Fernandes P.R. \& Duarte S.C. 2006. Tripanossomíase em bovinos no município de Formoso do Araguaia, Tocantins: relato de caso. Ciênc. Anim. Bras., Goiânia, 7(4):455-460.

Losos G.J. \& Ikede B.O. 1972. Review of pathology of diseases in domestic and laboratory animals caused by $T$. congolense, $T$. vivax, T. bruceii, T. rhodediense and T. congolense. Vet. Pathol. 9:267-274.

Otte M.J. \& Abuabara J.Y. 1991. Transmission of South American Trypanosoma vivax by the neotropical horsefly Tabanus nebulosus. Acta Tropica 49:73-76.

Otte M.J., Abaubara J.Y. \& Wells E.A. 1994. Tripanosoma vivax in Colombia: epidemiology and production losses. Trop. Anim. HIth Prod. 26:146-156.

Paiva F., Lemos R.A.A., Nakazato L., Mori A.E., Brum K.E. \& Bernardo K.C.A. 2000. Trypanosoma vivax em bovinos no Pantanal do Mato Grosso do Sul, Brasil: I. Acompanhamento laboratorial e anatomopatológico de rebanhos infectados. Revta Bras. Parasitol. Vet. 9(2):135141.

Riet-Correa F., Tabosa I.M., Azevedo E.O., Medeiros R.M.T., Simões S.V.D., Dantas A.F.M., Alves C.J., Nobre V.M.T., Athayde A.C.R., Gomes A.A. \& Lima E.F. 2003. Doenças de ruminantes e eqüinos no Semi-Árido da Paraíba. Semi-Árido em Foco, Patos, 1:49-52.

Rodrigues A., Fighera R.A., Souza T.M., Schild A.L., Soares M.P., Miliano J., Barros, C.S.L. 2005. Surtos de tripanossomíase por Trypanosoma evansi em eqüinos no Rio Grande do Sul: aspectos epidemiológicos, clínicos, hematológicos e patológicos. Pesq. Vet. Bras. 25(4):239249.

Sekoni V.O. 1994. Reproductive disorders caused by animal trypanosomiases: A review. Theriogenology 42(4):557-570.

Schunefeld A., Ruttcher D. \& Moloo S.K. 1987. The sensitivity to trypanocidal drugs of Trypanosoma vivax isolated in Kenya and Somalia. Trop. Med. Parasitol. 3(38):177-180.

Silva R.A.M.S. \& Dávila A.M.R. 2001. Bovine trypanosomosis due to Trypanosoma vivax in the German Bush province, Bolivia. Parasitología al día 25(1-2):65-67.

Silva R.A.M.S., Silva J.A., Schneider R.C., Freitas J., Mesquita D., Mesquita T., Ramirez L., Dávila A.M.R. \& Pereira M.E.B. 1996. Outbreak of trypanosomiasis due to Trypanosoma vivax (Ziemann, 
$1905)$ in bovines of the Pantanal, Brazil. Memórias Inst. Oswaldo Cruz 91(5):561-562.

Silva R.A.M.S., Ramirez E.S.S.L.L., Souza S.S., Ortiz A.G., Pereira S.R. \& Dávila A.M.R. 1999. Hematology of natural bovine trypanosomosis in the Brazilian Pantanal and Bolivian Wetlands. Vet. Parasitol. 85:8793.

Silva R.A.M.S., Sanchez V. \& Dávila A.M.R. 2003. Métodos de Diagnósticos Parasitológicos das Tripanosomoses Bovinas e Eqüinas. Circ. Téc. 41, Embrapa Pantanal, Corumbá, MS. 3p.

Silva R.A.M.S., Pellegrin A.O., Ramirez E.S.S.L.L. \& Dávila A.M.R. 2004. Abortos por Trypanosoma vivax no Pantanal Mato-Grossense e Bolívia. Doc. 75, Embrapa Pantanal, Corumbá, MS. 30p.
Stephen L.E. 1986. Trypanosomiasis: a veterinary perspective. Pergamon Press, New York. 533p.

Vargas T.M. \& Arellano S.C. 1997. La tripanosomiasis bovina en América Latina y el Caribe. Veterinaria, Montevideo, 33:17-21.

Ventura R.M., Paiva F., Silva R.A.M.S., Takeda G.F., Buck G.A. \& Teixeira M.M.G. 2001. Trypanosoma vivax: characterization of the spliced-leader gene for a Brazilian stock and species-specific detection by PCR amplification of an intergenic space sequence. Exptl Parasitol. 99:37-48.

Zapata A. 1931. La afección de los ganados llamada vulgarmente "huequera", "secadera", "cachohueco". Revta Med. Vet., Buenos Aires, 3:165-180. 